\title{
Empresas, inovação e território na alta tecnologia: 0 caso da Itália
}

FRANGESGO RAMELLA:

\section{Resumo}

Nas abordagens analíticas predominantes, as atividades inovadoras são concebidas como sistemas de interação, envolvendo uma pluralidade de atores, econômicos e não econômicos, em que a dimensão geográfica desempenha um papel importante. Mas, se, por um lado, o vínculo entre o território e a inovação é geralmente reconhecido, por outro, a relação específica com as empresas é menos clara. Para abordar este tópico, o artigo apresenta os resultados da pesquisa realizada com sistemas e empresas de inovação de alta tecnologia e média-alta tecnologia, na Itália. São dois os objetivos: 1) revelar indutivamente - isto é, a partir de uma análise de micronível - a relevância do território no desenvolvimento da inovação em setores de alta tecnologia; 2) destacar as características distintivas das empresas inovadoras e seus vínculos com o território.

Palavras-chave: Inovação e território. Geografia da inovação. Empresas de alta tecnologia. Sistemas locais de inovação. Itália.

\footnotetext{
* Universidade de Torino, Itália.
} 


\title{
Enterprises, innovation and territory in high-tech sectors: the case of Italy
}

\begin{abstract}
In the prevalent analytical approaches, innovative activities are conceived as systems of interaction involving a plurality of actors, economic and non, and where the geographical dimension plays a major role. But if, on one hand, the link between territory and innovation is generally recognized, on the other the specific relationship with enterprises is less clear. To address this topic, the article presents the results of research carried out on high-tech and medium-high tech innovation systems and enterprises in Italy. The goal is twofold: 1) to bring out inductively that is starting from a micro-level analysis - the relevance of the territory in the development of innovation in high-tech sectors; 2 ) to highlight the distinctive characteristics of innovative enterprises and the links with their territories.
\end{abstract}

Keywords: Innovation and territory. Geography of innovation. High-tech enterprises. Local systems of innovation. Italy.

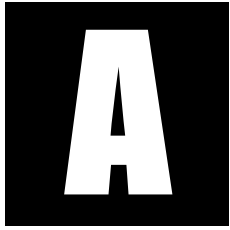

inovação requer a contribuição de uma pluralidade de atores, econômicos ou não. Por isso, nas abordagens de análise hoje prevalentes, a circulação das informações, a criação de novas ideias e as próprias atividades inovadoras são concebidas como sistemas complexos de interação, nos quais a dimensão territorial assume uma posição de grande relevância. Mas, se o papel do território como recurso importante para a inovação é, em geral, reconhecido, já sua relação específica com as empresas não é tão evidente. Certamente, essas podem obter vantagem de uma série de bens coletivos que constituem economias externas materiais e imateriais. Por exemplo, a presença de universidades e estruturas de pesquisa, de elevadas competências em termos de capital humano e 
de fornecedores especializados. Mas nem todas as empresas são capazes de usufruir adequadamente desses recursos. E nem todos os territórios conseguem valorizar as estruturas de pesquisa e de formação de que dispõem para favorecer a inovação. Em suma, a análise das relações entre empresas, inovação e território merece ser aprofundada.

A Itália representa um caso particularmente interessante para a análise dessas questões, uma vez que incorpora um modelo regionalizado de capitalismo com um sistema nacional de inovação fraco e uma forte aglomeração territorial da atividade produtiva (Trigilia; Burroni, 2009; Ramella; Trigilia, 2010a, 2010b; Burroni; Trigilia, 2011; Donatiello; Ramella, 2017). Não por acaso, precisamente na Itália, desenvolveu-se uma escola analítica, de vertente interdisciplinar, que tem estudado o desenvolvimento local com foco, particularmente, nos distritos industriais da chamada "Terceira Itália"1 (Becattini, 1990; Becattini et al., 2009; Bagnasco, 1977; Trigilia, 1990). Essa corrente de estudos destacou dois elementos de grande interesse: a) a forte interrelação existente, em certos territórios, entre os sistemas das empresas e as comunidades locais; b) as modalidades inovadoras específicas - de tipo coletivo e incremental - que se empregam nesses contextos.

No passado, os pesquisadores italianos (economistas e sociólogos) concentraram-se principalmente nos setores produtivos tradicionais, de média-baixa tecnologia. Todavia, a mesma abordagem analítica pode ser utilizada para estudar os de alta tecnologia. Aliás, é exatamente nesses últimos que se mostra mais evidente a complementaridade existente entre os recursos internos e aqueles externos às empresas; isto é, a interdependência entre as estratégias empresariais, as redes de colaboração e os bens coletivos locais. Para compreender essa interrelação, que pode

\footnotetext{
${ }^{1}$ Com esse termo, faz-se referência às regiões do Centro da Itália (Emília-Romanha, Toscana, Marche e Úmbria) e do Nordeste (Vêneto, Trentino-Alto Ádige e Friul-Veneza Júlia), caracterizadas por um "modelo de desenvolvimento difuso", isto é, não concentrado nas grandes cidades metropolitanas e baseado em uma elevada presença de pequenas e médias empresas manufatureiras, frequentemente localizadas nos distritos industriais.
} 
dar vida a verdadeiros sistemas regionais e locais de inovação, é essencial uma abordagem integrada, com explicações conduzidas a uma pluralidade de níveis geográficos e analíticos, que levem em consideração: 1) os "fatores de agência", isto é, os atores da inovação; 2) os "fatores relacionais", isto é, as relações que os unem; 3) os "fatores contextuais", isto é, os contextos setoriais e territoriais em que operam.

Para abordar esses temas, farei uso de algumas pesquisas conduzidas sobre os sistemas territoriais da alta e média-alta tecnologia na Itália e, em particular, dos resultados de um estudo longitudinal sobre uma amostra de mais de 400 empresas italianas que obtiveram patentes da European Patent Office (EPO) nos setores da mecânica e de alta tecnologia (doravante, patentes-EPO e empresas-EPO). São três os objetivos a que me proponho: 1) fazer emergir, indutivamente, isto é, partindo de uma análise de âmbito micro, a relevância do território na inovação pelos setores de alta tecnologia; 2) evidenciar as características distintivas das empresas inovadoras e seus vínculos com o território; 3) evidenciar as conexões entre suas estratégias organizacionais internas, as parcerias externas para inovação e o desempenho econômico, analisando seu comportamento durante a crise econômica internacional.

O artigo está organizado do seguinte modo. Na próxima seção (2), apresento - de maneira sintética e sem pretensão de esgotar - algumas contribuições que salientaram a importância da proximidade territorial para explicar a performance inovadora das empresas. Nas três seções seguintes, descrevo o desenho da pesquisa (seção 3), o perfil socioterritorial das patentes (seção 4) e das empresas-EPO italianas (seção 5), bem como a relevância das parcerias inovadoras (seção 6). Por fim, nas duas últimas seções (7-8), analiso o desempenho econômico dessas empresas e faço algumas considerações de cunho mais geral. 


\section{Mapas da inovação}

Nas décadas passadas, o debate sobre a globalização e sobre as novas tecnologias da informação, com frequência referiu-se a um "fim da geografia". A revolução dos meios de comunicação e a redução das barreiras (normativas e tarifárias) à movimentação de mercadorias e de capitais criaram a hipótese de uma "morte da distância" (Cairncross, 1997). Da perspectiva econômica, o que sugerem esses debates é que a mudança tecnológica modificou radicalmente o modelo de desenvolvimento. De um lado, a economia baseia-se, cada vez mais, na utilização de conhecimentos e bens imateriais (como a criatividade) enquanto, de outro, assiste-se a uma drástica reorganização espacial das atividades produtivas, que tende a relativizar a influência da "distância física". Foi um economista inglês, Richard O'Brien (1992, p. 1), ao estudar as relações financeiras internacionais, que lançou a ideia do fim da geografia, definindo-o como "um estado do desenvolvimento econômico em que a localização geográfica já não importa".

Todavia, a evidência empírica contradiz essa tese. De fato, ainda hoje, a produção da riqueza e do bem-estar não ocorre em qualquer lugar do mundo. As empresas - especialmente as industriais - adensam-se em lugares específicos, onde encontram fornecedores especializados, serviços adequados e uma mão de obra qualificada. Não é de surpreender, portanto, que nos mesmos anos em que se falava de globalização, outros estudiosos estivessem redescobrindo a importância da organização espacial dos fenômenos sociais e econômicos. Essa redescoberta do território está também na base da geografia da inovação. Na verdade, nem mesmo a inovação ocorre em qualquer lugar, mas sim tende a aglomerar-se em determinados locais. Isso ocorre, essencialmente, por três motivos.

O primeiro motivo é que a introdução de novos produtos e processos produtivos requer a colaboração de uma pluralidade de atores, econômicos não econômicos (empresas, universidades, centros de pesquisa, 
serviços avançados etc.); isto é, configura-se como um processo conjunto de criação e aplicação de novos conhecimentos, que é facilitado pela proximidade territorial (Asheim; Gertler, 2005). O segundo motivo refere-se à importância dos bens coletivos locais para a competição, os quais criam vantagens para as empresas, tanto por reduzirem seus custos de produção, quanto por aumentarem sua capacidade inovadora (Crouch et al., 2001). Essas economias externas podem ser de tipo tangível ou intangível: entre as primeiras, estão as infraestruturas e os serviços locais; entre as segundas encontram-se tanto os recursos cognitivos quanto os normativos, como o conhecimento contextualizado², as convenções, as normas de reciprocidade e o capital social local.

O terceiro motivo refere-se aos spillover de conhecimento, ou seja, à difusão - mais ou menos voluntária - das informações e dos conhecimentos que são produzidos nas atividades de pesquisa e de inovação. Os desempenhos inovadores das empresas, na verdade, não dependem somente dos recursos que essas empregam na pesquisa, mas também daqueles investidos por outras empresas do mesmo setor ou de setores contíguos, como também pelas universidades, pelos centros de pesquisa etc. Porém, a apropriação desses spillovers está vinculada à proximidade da fonte dos novos conhecimentos. Uma proximidade que se torna tanto mais relevante quanto mais se utiliza na inovação o "conhecimento tácito" que, diferentemente do explícito, é difícil de ser traduzido de forma escrita ou codificada e de ser transmitido a outros (Polanyi, 1966). O conhecimento tácito se produz através da experiência acumulada em contextos específicos, e é incorporado (Pavitt, 2002); está, portanto, indissoluvelmente ligado à pessoa que o detém e é transmitido através de

\footnotetext{
${ }^{2}$ Trata-se de conhecimentos e competências especializados que se referem especificamente ao contexto territorial e baseiam-se em um mix de componentes cognitivos e normativos. Esse conhecimento contextual é sobretudo tácito e informal e pode ser adquirido somente através de longos processos de socialização que requerem um compartilhamento de experiências em nível local (Becattini; Rullani, 2000, p. 105).
} 
uma "comunicação densa", baseada em relações pessoais. A construção dessas relações requer tempo e confiança e é, portanto, facilitada pela proximidade. É, de fato, difícil fazê-lo viajar por longas distâncias, porque é produzido em nível regional/local ao qual permanece ligado. Como foi observado, é spatially sticky (Gertler, 2003).

Uma "dimensão tácita" está presente também no saber científico-tecnológico, e é por esse motivo que a sua transmissão ocorre mediante trocas pessoais (Dasgupta; David, 1994, pp. 493-4). Até mesmo nos casos em que as empresas se valem dos canais típicos da open science (por exemplo, publicações, conferências etc.), as informações assim adquiridas são frequentemente integradas mediante contatos diretos com os pesquisadores universitários (Cohen et al., 2002, p. 17). Essas relações envolvem principalmente as universidades do território, sobretudo quando as questões se referem a atividades pouco padronizadas, que requerem o compartilhamento de conhecimentos contextualizados: informações específicas sobre as empresas e sobre seu contexto territorial (Geuna; Rossi, 2015).

Esses processos de aprendizagem localizados, em vez de desaparecer, assumiram relevância especial precisamente no contexto da globalização. Quanto mais o conhecimento codificado circula facilmente através das redes globais, mais o conhecimento tácito e contextual torna-se um bem estratégico que produz vantagens competitivas difíceis de serem imitadas (Maskell; Malmberg, 1999). Enfim, na base da geografia da inovação reside a ideia de que a produção e a difusão de um novo conhecimento economicamente relevante ocorram em nível territorial mediante dinâmicas de learning through interacting (Lundvall; Johnson, 1994).

Várias correntes da literatura contribuíram para a redescoberta dos "territórios da inovação". Alguns economistas exploraram tanto a existência de spillovers geograficamente vinculados (Jaffe et al., 1993), quanto os efeitos localizados da pesquisa universitária, relacionados com o capital 
humano fornecido pelos star scientists - pesquisadores particularmente produtivos e inovadores que representam um fator de atração para as empresas inovadoras (Zucker; Darby, 1996). Outros têm trabalhado sobre sistemas de inovação nacionais e regionais e sobre as vantagens competitivas criadas pelas "economias de aglomeração", isto é, os benefícios econômicos que as empresas obtêm por estarem geograficamente localizadas umas próximas às outras (Ramella, 2017b). Em geral, os economistas têm salientado, sobretudo, o lado cognitivo e experiencial do conhecimento tácito, e a importância da proximidade territorial para a difusão dos conhecimentos. A geografia econômica e a sociologia econômica evidenciaram também a dimensão socioinstitucional que modela tanto as transações econômicas quanto os processos de aprendizagem. Ambos dependem, de fato, "das normas, convenções, valores, expectativas e rotinas compartilhadas, que decorrem de infraestruturas institucionais comumente experimentadas" (Gertler, 2003, p. 91, itálico no original).

Além disso, nos últimos anos, os geógrafos econômicos têm relativizado os conceitos de distância e proximidade, reinterpretando-os em termos relacionais (Rodríguez-Pose, 2011). Em outras palavras, a distância foi socializada e a proximidade tornou-se multidimensional: existem diversos tipos de relações entre os atores, às quais correspondem diferentes dimensões de distância/proximidade (cognitiva, organizacional, social, institucional, geográfica), para as quais a proximidade territorial é mais ou menos relevante (Boschma, 2005). A contribuição da sociologia se fez no mesmo tom, o que possibilitou um melhor entendimento da construção social da inovação em diversas escalas analítico-territoriais (Trigilia, 2007). Nos níveis macro (global e nacional) e meso (regional e local), os sociólogos têm explorado a relação entre os diversos modelos de capitalismo e os regimes de inovação, salientando a importância dos "modos de regulamentação". No nível micro, por outro lado, têm aprofundado o enraizamento social das atividades 
econômicas, evidenciando a influência das redes de colaboração entre os atores da inovação ${ }^{3}$. O conjunto dessas reflexões tornou as coordenadas territoriais menos estáticas e mais processuais, transformando-as em um continuum de relações de múltiplas escalas, isto é, relações que se desenvolvem em diferentes escalas geográficas.

\section{O desenho de pesquisa}

Como antecipei, a Itália representa um caso particularmente interessante para analisar a dimensão territorial da inovação e a relação entre as empresas e os contextos locais. Para tanto, Carlo Trigilia e eu conduzimos uma pesquisa empírica sobre o setor de alta e média-alta tecnologia, a qual estruturou-se em duas fases: a) a primeira focou-se na análise territorial da atividade de registro de patentes; b) a segunda concentrou-se no estudo das empresas com patentes europeias ${ }^{4}$.

\section{a) A análise territorial: as patentes europeias}

A primeira fase da pesquisa foi dedicada a retraçar a geografia da inovação na Itália, utilizando-se como indicador os requerimentos de patentes, por empresas italianas, depositados junto à entidade europeia de proteção do direito de propriedade intelectual, e estabelecendo como marco temporal o período de dez anos que antecedeu à crise econômica

\footnotetext{
${ }^{3}$ Para um aprofundamento, ver Ramella, 2017b.

${ }^{4}$ Além do exame das patentes e do levantamento das empresas, que são descritos neste artigo, a investigação inclui também 700 entrevistas com questionários e 50 entrevistas em profundidade com inventores italianos, identificados através da documentação de patentes. As reflexões do presente artigo, especialmente aquelas relacionadas ao trabalho em equipe nas equipes de pesquisa e desenvolvimento e ao modelo organizacional das empresas-EPO, baseiam-se também nessas últimas entrevistas.
} 
internacional (1995-2004) ${ }^{5}$. As informações sobre patentes foram coletadas a partir da base de dados do Instituto Europeu de Patentes (EPO - European Patent Office - http://ep.espacenet.com) e, para identificar os setores de alta e média-alta tecnologia, foi utilizada a classificação Eurostat-OCDE, que subdivide a atividade industrial em quatro categorias, segundo uma ordem decrescente de intensidade tecnológica. Finalmente, a localização geográfica dessas patentes foi reconstruída segundo um nível territorial especialmente detalhado, de âmbito sub-regional: aquele dos "sistemas locais de trabalho italianos". Esses sistemas são unidades territoriais criadas pelo instituto central de estatística italiano (Istat) com base no "movimento pendular casa-trabalho" ${ }^{6 "}$ localizando as áreas em que se verifica uma substantiva "limitação" dos deslocamentos interurbanos cotidianos da população por motivos de trabalho.

b) A sondagem das empresas-EPO

Na segunda fase da pesquisa, o foco analítico deslocou-se das características socioeconômicas dos territórios para os aspectos organizativos e de relações das empresas. Esta parte da pesquisa teve como referência as empresas de alta tecnologia e do setor de mecânica ${ }^{7}$. A pesquisa foi do tipo painel, isto é, as mesmas empresas foram entrevistadas em dois momentos distintos. Para identificar o universo de referência, forma

\footnotetext{
${ }^{5}$ As patentes representam um indicador já consolidado na literatura especializada sobre a inovação (sobretudo na econômica). Desse indicador, foram evidenciadas não somente as potencialidades analíticas, mas também os limites. Para maiores detalhes sobre esses aspectos, remeto a Ramella e Trigilia (2010a).

${ }^{6}$ (NT): O movimento pendular refere-se aos deslocamentos de pessoas para trabalhar ou estudar em municípios diferentes daquele de residência.

${ }^{7}$ No que concerne a esta parte da pesquisa, com referência ao setor de média-alta tecnologia, decidimos concentrá-la exclusivamente nas empresas mecânicas para possibilitar uma análise mais específica. Deve-se ter em conta que a indústria mecânica responde, sozinha, por cerca de um terço das patentes EPO italianas e que, portanto, mesmo focalizando a pesquisa sobre um único setor - ao contrário do que se fez para a alta tecnologia - assegurou-se um adequado número de casos.
} 
analisados 5.313 patentes europeias concedidas a empresas requerentes italianas no setor de alta tecnologia e de mecânica. A partir desta base, foi extraída uma lista de 1.504 empresas ativas (com uma média de 3,5 patentes cada uma), às quais foi aplicado um questionário por via eletrônica (método CAWI: computer assisted web interviewing). A primeira série de entrevistas (EPO-survey 2010) foi conduzida durante os primeiros meses de 2010 e um total de 407 firmas responderam o questionário - no todo ou em parte - representando uma taxa de resposta de $27 \%$. A segunda série de entrevistas (EPO-survey 2012) foi realizada nos últimos meses de 2012 utilizando: a) o mesmo grupo de empresas que respondeu à primeira survey; b) as mesmas técnicas de pesquisa. As empresas que responderam à segunda entrevista totalizaram 155, com uma taxa de $40 \%$ das empresas que ainda permaneciam ativas $(384)^{8}$.

\section{Os territórios de alta tecnologia na Itália}

A pesquisa sobre patentes europeias evidenciou diversos elementos. O primeiro é a relevância dos setores de alta e média-alta tecnologia na atividade de patenteamento italiana: eles representam, respectivamente, $24 \%$ e $50 \%$ do total nacional. O segundo é o adensamento das patentes nas regiões mais desenvolvidas do País e em particular nas grandes cidades metropolitanas do Centro-Norte e nas cidades médias da Terceira Itália (Fig. 1). O terceiro elemento - aquele que mais interessa salientar aqui - é a forte concentração da inovação em um número muito reduzido

\footnotetext{
${ }^{8} \mathrm{~A}$ análise do perfil das empresas que não responderam ao questionário não indicou qualquer distorção sistemática da amostra com relação ao universo de referência. Na primeira sondagem, efetuou-se um controle da amostra (407 empresas) em relação ao universo (1504 empresas) com base na localização geográfica e no setor a que pertencem as empresas. Na segunda sondagem, além das variáveis anteriores, a amostra (155 empresas) foi comparada ao universo (407 empresas) também com base no número de empregados. Em todos os casos, os desvios amostra/ universo resultaram sempre bastante reduzidos, variando entre $3 \%$ e I,8\% (este último percentual refere-se à segunda sondagem e à comparação com a variável dimensional.
} 
de polos territoriais. De fato, os sistemas líderes da inovação na mecânica e na alta tecnologia, mesmo representando uma cota restrita dos sistemas locais de trabalho italianos (pouco mais de 6\%), abrangem a grande maioria das patentes-EPO: $70 \%$ na mecânica e $84 \%$ na alta tecnologia 9 .

Figura 1. A geografia das patentes-Epo na Itália com base nos sistemas locais do trabalho

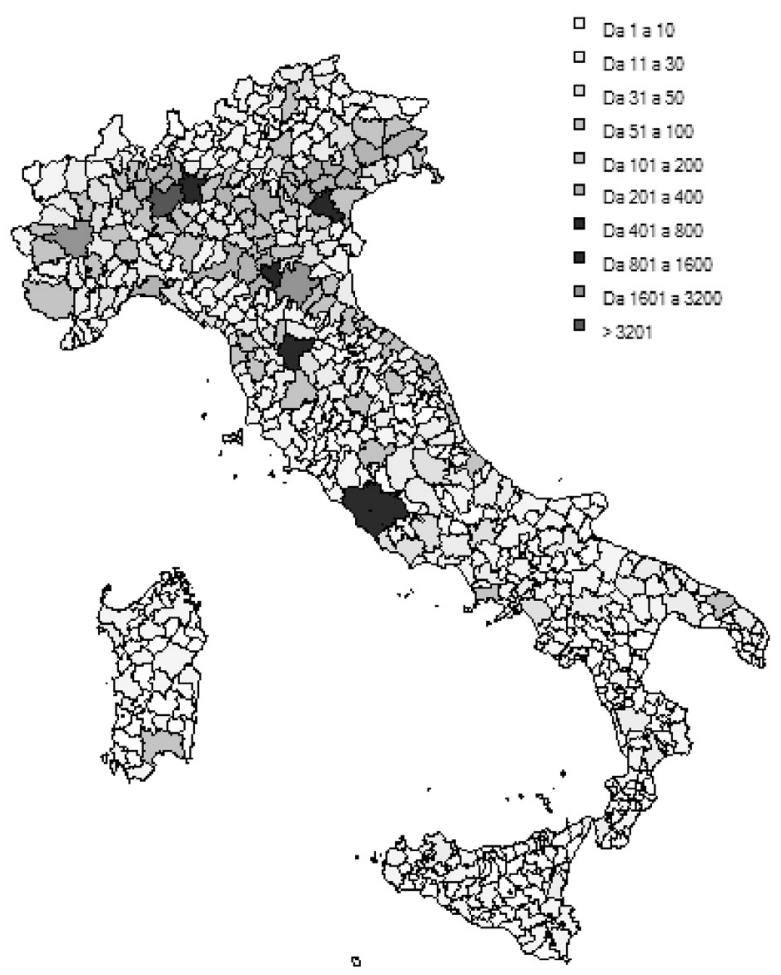

Fonte: pesquisa sobre patentes-EPO

${ }^{9}$ Os sistemas líderes de inovação foram identificados com base nos requerimentos de patentes: representam o primeiro decil da classificação dos sistemas locais de trabalho que, na década investigada, apresentaram pelo menos um requerimento ao European Patent Office. 
O perfil territorial desses sistemas líderes de inovação resulta, porém, significativamente diverso nos dois setores. No de alta tecnologia, emerge um perfil radicado nas cidades metropolitanas, com um bom número de universidades e de pós-graduados, de grandes empresas e de um setor de serviços avançado. Também a qualidade de vida e a presença de bens coletivos locais se mostram elevadas. Mesmo no setor de mecânica, emerge um contexto socioinstitucional muito qualificado, com uma infraestrutura superior ao dado médio nacional. Nesse caso, porém, nota-se um adensamento relativamente maior nas regiões e nos sistemas produtivos manufatureiros da Terceira Itália, com uma presença significativa das médias empresas. A dimensão urbana tem um papel importante, mas registra-se uma menor quantidade de serviços avançados, de universidades e de pós-graduados.

O que distingue os sistemas líderes de inovação da mecânica e da alta tecnologia? Confrontados com outros sistemas locais de controle - caracterizados por um bom aparato empresarial e produtivo nos dois setores, mas com uma capacidade de patenteamento decididamente inferior -, aquilo que mais diferencia os sistemas líderes em relação aos outros é a qualidade dos bens coletivos locais (Biagiotti, 2010). De fato, os sistemas locais pertencentes ao grupo de controle (aqueles com poucas patentes) evidenciam um forte subdimensionamento nas redes de telecomunicação, uma menor dotação de bens coletivos econômicos e sociais, não somente em relação aos sistemas líderes, mas também à média nacional. A fraca qualidade do contexto socioinstitucional obstaculiza, por isso, suas potencialidades inovadoras. Portanto, para que se desenvolva um sistema local fortemente inovador, é necessária, além de uma adequada base econômica e empreendedora, também uma forte estrutura institucional de suporte: um bom aparato de capital humano e de centros universitários, uma rede de infraestrutura desenvolvida, serviços qualificados, uma boa qualidade de vida. 
A ênfase colocada na aglomeração territorial da inovação - isto é, nos fatores contextuais - não deve, porém, induzir a deixar de lado a relevância das escolhas empreendedoras. Como foi verificado, um erro comum a diversas abordagens sistêmicas e institucionais é ler o comportamento dos atores unicamente a partir das características dos contextos em que se movem (Gertler, 2010). Ao contrário, as empresas possuem certa autonomia: não são exclusivamente rule-takers, mas também rule-makers. Essas, de fato, derivam consistentes graus de liberdade reelaborando de modo reflexivo o repertório de capacidades e experiências herdado do próprio passado, e isso de maneira parcialmente independente do setor e do país em que operam. Susan Berger definiu essa abordagem como o "modelo das heranças dinâmicas" (2005). O estudo da inovação, portanto, não pode prescindir das estratégias competitivas e organizacionais das empresas.

\section{O perfil das empresas-EPO}

Para aprofundar esta questão, desenvolvemos as duas sondagens sobre as empresas-EPO mencionadas na seção 3. As entrevistas focalizaram três quesitos principais: 1) quais são as características distintivas dessas empresas? 2) que relações de colaboração possuem com atores externos e em que escalas territoriais? 3) as escolhas organizacionais internas e as colaborações externas (innovative partnership) influenciaram seus resultados econômicos? No que segue, apresentam-se respostas a essas perguntas, com as seções 6 e 7 dedicadas respectivamente à segunda e à terceira.

Partamos da primeira questão. Os dados de registro e o perfil estrutural evidenciam a solidez das empresas-EPO. Quase 80\% delas estão ativas há mais de vinte anos, possuem um bom giro de faturamento e alta produtividade do trabalho. Apesar do nítido predomínio de pequenas e 
médias empresas (menos de 250 empregados), são sobretudo aquelas de médio (50-249 empregados) e grande porte (mais de 250 empregados) as que estão sobrerrepresentadas em relação aos dados nacionais (Tab.1). Em geral, são empresas voltadas aos mercados nacionais e internacionais, altamente competitivos, oferecendo - sobretudo no setor mecânico - bens intermediários e equipamentos (componentes e maquinários) que outras empresas utilizam para a produção de mercadorias destinadas aos consumidores finais. O capital humano é um dos recursos-chave para fazer frente a esses cenários competitivos. Efetivamente, evidencia-se um perfil altamente qualificado de pessoal - 49\% dos empresários são pósgraduados e metade dos empregados possui um diploma de escola superior ou um título universitário. Além disso, muita atenção é dedicada à formação interna. No geral, tem-se um grupo de empresas robustas, com bom desempenho também em termos de exportações, como se evidencia claramente na comparação com a média das empresas italianas que operam nesse mesmo setor (Tabela 1). Sua "solidez", portanto, é o primeiro aspecto distintivo das empresas-EPO. 
Tabela 1. Perfil das empresas-EPO em comparação aos valores médios nacionais

\begin{tabular}{|c|c|c|c|c|c|c|}
\hline & \multicolumn{3}{|c|}{ Empresas-EPO } & \multicolumn{3}{|c|}{ Empresas italianas } \\
\hline & $\begin{array}{c}\text { Alta } \\
\text { tecnologia }\end{array}$ & Mecânica & Total & $\begin{array}{c}\text { Alta } \\
\text { tecnologia }\end{array}$ & Mecânica & Total \\
\hline \multicolumn{7}{|l|}{ Empregados } \\
\hline Até 9 empregados & 10,1 & 8,7 & 9,1 & 88,8 & 75,8 & 81,3 \\
\hline $\begin{array}{c}10-49 \\
\text { empregados }\end{array}$ & 31,9 & 38,1 & 36,3 & 8,7 & 19,8 & 15,1 \\
\hline $\begin{array}{c}\text { 50-249 } \\
\text { empregados }\end{array}$ & 37,7 & 31,2 & 33,1 & 2,0 & 3,8 & 3,1 \\
\hline $\begin{array}{l}\text { Mais de } 250 \\
\text { empregados }\end{array}$ & 20,3 & 22,0 & 21,5 & 0,5 & 0,6 & 0,5 \\
\hline Total & 100,0 & 100 & 100 & 100,0 & 100 & 100 \\
\hline \multicolumn{7}{|l|}{$\begin{array}{l}\text { Até } 19 \\
\text { empregados }\end{array}$} \\
\hline $\begin{array}{l}\text { Faturamento } \\
\text { (em mil Euros) }\end{array}$ & 2.116 & 2.524 & 2.419 & 289 & 567 & 444 \\
\hline $\begin{array}{l}\text { Faturamento por } \\
\text { empregado } \\
\text { (em mil Euros) }\end{array}$ & 181 & 268 & 244 & 104 & 130 & 121 \\
\hline $\begin{array}{l}\text { \% de faturamento } \\
\text { com exportação }\end{array}$ & 44,0 & 42,5 & 42,9 & 14,3 & 24,8 & 21,8 \\
\hline \multicolumn{7}{|l|}{$\begin{array}{l}\text { Mais de20 } \\
\text { empregados }\end{array}$} \\
\hline $\begin{array}{l}\text { Faturamento } \\
\text { (em mil Euros) }\end{array}$ & 352.108 & 57.538 & 142.339 & 34.860 & 21.273 & 24.974 \\
\hline $\begin{array}{l}\text { Faturamento por } \\
\text { empregado } \\
\text { (em mil Euros) }\end{array}$ & 378 & 215 & 262 & 254 & 248 & 250 \\
\hline $\begin{array}{l}\text { \% de faturamento } \\
\text { com exportação }\end{array}$ & 53,4 & 63,8 & 60,7 & 36,5 & 52,6 & 46,5 \\
\hline
\end{tabular}

Fonte: Elaborado pelo autor. 
O segundo aspecto é que são empresas que investem muito em pesquisa e desenvolvimento (P\&D). Elas dedicam, em média, cerca de 5\% do faturamento no setor de mecânica, e 7\% no de alta tecnologia. Trata-se de recursos consideráveis, sobretudo no que se refere ao primeiro dos dois setores ${ }^{10}$. O trabalho de pesquisa é desenvolvido através dos times de projeto específicos, presentes em 79\% das empresas-EPO. O trabalho de grupo é supervisionado por gerentes que asseguram a coordenação e a integração dos vários projetos. A organização dessas equipes segue um modelo preciso, marcado pela coesão e pela flexibilidade: a coordenação por parte de uma ou poucas pessoas é acompanhada por uma forte autogestão do trabalho de pesquisa. Trata-se, portanto, de pequenos grupos de trabalho, fortemente integrados, dentro dos quais, os pesquisadores gozam de uma ampla autonomia no desenvolvimento das próprias tarefas (Ramella; Trigilia, 2010b).

Junto a esses elementos organizacionais, devem ser consideradas as competências e os conhecimentos disponíveis no interior da equipe. Em 59\% dos casos, esses são definidos pelos entrevistados como afins: todos os pesquisadores pertencem ao mesmo setor científico, mas com especializações bastante diferenciadas. Em 30\% das empresas, as competências são fortemente heterogêneas e percebe-se a colaboração de pesquisadores pertencentes a diversos departamentos científico-tecnológicos. Enfim, nos restantes $11 \%$ dos casos, operam equipes com competências muito homogêneas. A grande maioria dessas equipes, além disso, vale-se de conhecimentos adquiridos também por fontes externas, tanto de mercado (fornecedores, clientes, empresas concorrentes etc.) quanto técnico-científicas (pesquisadores, consultores etc.). Os recursos cogni-

\footnotetext{
${ }^{10}$ Para avaliar a significância desse dado, vale observar que, no mesmo período, em grande parte das economias avançadas, os gastos com inovação giraram em torno de 1-2\% do faturamento da empresa e a cota destinada especificamente com P\&D representava cerca da metade disso (OECD, 2010, p. 78).
} 
tivos diversificados (extensão e pluralidade de competências) presentes nas empresas influenciam de modo significativo a sua absorptive capacity - isto é, a capacidade de absorver recursos externos - e seu desempenho inovador (Cohen; Levinthal, 1990). Em geral, a análise desenvolvida sobre as empresas-EPO mostra que um déficit na diversificação obstaculiza a produção de ideias novas e realmente criativas que requerem, além da sinergia na equipe, também a circulação de conhecimentos de tipo diverso (Ramella, 2017a; 2017b).

\section{As parcerias inovadoras}

Como já mencionado, porém, a flexibilidade organizacional e as competências internas por si sós não são suficientes para garantir um bom desempenho. A partir da metade dos anos de 1990, os estudos sobre a inovação mostraram um interesse crescente nas relações interorganizacionais, por causa do crescimento exponencial das relações de colaboração entre as empresas, que têm interessado sobretudo aos setores de alta tecnologia (Hagedoorn, 2002, p. 479-82; Powell; Grodal, 2005). Em outros termos, muitas empresas começaram a aplicar uma estratégia de open innovation, como alternativa ao modelo fechado de inovação típico das empresas verticalmente integradas (Chesbrough, 2003). Diferentemente deste último, o modelo aberto parte do pressuposto de que os conhecimentos úteis para inovação estão dispersos entre uma pluralidade de atores diversos, por isso, torna-se necessário abrir os limites da empresa e desenvolver parcerias externas.

Entre as empresas-EPO, essas estratégias colaborativas são muito difundidas. Cerca de $70 \%$ delas instaurou ao menos uma parceria em atividades de pesquisa e inovação com outras empresas (59\%) e/ou com um centro de pesquisa ou uma universidade (54\%). Confrontados com 
os dados médios nacionais, esses valores resultam extraordinariamente elevados. De fato, no mesmo período em que conduzimos a pesquisa, registrava-se, na Itália, o percentual mais baixo da Europa de empresas que mantinham acordos de cooperação para a inovação com parceiros externos: $13 \%$ contra uma média europeia de $25 \%$ (CIS, 2010). Os percentuais aumentavam no setor de alta tecnologia, mas também nesse setor a Itália permanecia nos últimos lugares da classificação europeia. O ponto a ser salientado é a difusão das parcerias inovadoras.

Mas de que colaboração se trata? As parcerias baseadas em redes curtas (de âmbito local/regional) são muito difundidas: 48\% das empresas-EPO possui ao menos uma colaboração com empresas e universidades do próprio território. Mas o mesmo vale para as parcerias baseadas em redes longas (extrarregionais): $42 \%$ das empresas possui colaborações com empresas nacionais e 34\% com empresas estrangeiras; $34 \%$ com universidades ou centros de pesquisas nacionais e $17 \%$ com institutos estrangeiros. Portanto, as redes curtas não devem ser contrapostas às longas, pois, na maioria dos casos, elas coexistem e alimentam-se reciprocamente. Entre as empresas com ao menos uma parceria, aquelas que combinam redes curtas e redes longas constituem a maioria (56,3\%); enquanto as empresas com colaborações somente regionais/locais ou extrarregionais representam, respectivamente, $14,0 \%$ e $29,7 \%$.

Do mesmo modo, seria um erro identificar essas parcerias inovadoras, que difundem recursos diversificados, com relações reguladas exclusivamente pelo mercado. Solicitou-se aos entrevistados classificar os acordos com outras empresas, distinguindo aquelas com as quais possuem relações de tipo ocasional baseadas exclusivamente em uma lógica de mercado (vínculos de mercado), daquelas com as quais possuem relações consolidadas no tempo, em que a confiança tem um papel de primordial (vínculos socioeconômicos). Em dois terços dos casos, é exatamente esse 
segundo tipo de vínculo que prevalece. E isso sem considerar os setores, as dimensões das empresas e a localização geográfica do parceiro. Assim, à luz desses dados, um outro elemento distintivo das empresas-EPO é sua integração (embeddedness), isto é, o enraizamento social e territorial de suas atividades inovadoras.

Essas redes de aprendizagem interativa não devem, contudo, ser isoladas das características internas das empresas-EPO, pois incidem no seu desempenho somente através da mediação de estratégias gerenciais específicas. Isso emerge claramente através de um indicador que mede um modelo organizacional voltado à integração estratégica. Esse índice reúne duas dimensões: a) a presença de pós-graduados e a presença de atividades de formação desenvolvidas dentro da empresa (capital humano); b) a autonomia das equipes de pesquisa e dos pesquisadores associada a um forte envolvimento dos empregados com os objetivos da empresa (flexibilidade e coesão organizacional) ${ }^{11}$.

Em outros termos, o índice elucida uma cultura de empresa orientada à colaboração, que se fundamenta em uma estratégia empreendedora voltada a valorizar o capital humano e em um modelo organizacional flexível e descentralizado, que se vale da participação dos pesquisadores e dos empregados. Ou seja, trata-se de learning organizations (Arundel et

\footnotetext{
${ }^{11} \mathrm{O}$ índice de integração estratégica foi obtido a partir de análises semântica (afinidade dos conteúdos) e estatística (análise fatorial) aplicada a cinco variáveis: (v1) o percentual de empregados pós-graduados; (v2) a presença de atividades de formação internas; (v3) a autonomia operativa da equipe de pesquisa; ( $\mathrm{v} 4$ ) a autonomia dos pesquisadores da equipe; ( $\mathrm{v} 5$ ) a existência de um forte envolvimento dos empregados com os objetivos da empresa. A análise fatorial (método das componentes principais com rotação oblíqua) levou à extração de dois fatores que, juntos, explicam 50,1\% da variância, e sobre essa base construíram-se dois índices (campo de variação 0-1). O primeiro - capital humano - baseia-se nas primeiras duas variáveis $(\mathrm{v} 1+\mathrm{v} 2)$, enquanto o segundo - flexibilidade e coesão organizacional - baseia-se nas últimas três variáveis $(v 3+v 4+v 5)$. Os dois índices foram depois agregados ao índice de integração estratégica (campo de variação 0-2), que foi utilizado exclusivamente para fins de tipologia, isto é, para identificar um tipo organizacional caracterizado por elevados níveis de capital humano flexibilidade e coesão organizacional (pontuação do índice $=>1,5$ ).
} 
al., 2007), em que os recursos internos potencializam a absorptive capacity em relação ao externo. No caso das empresas-EPO, altos índices de integração estratégica estão associados - também em igualdade de setor e de porte - a um número maior de parcerias inovadoras (Tabela 2) e como se verá adiante - a melhores desempenhos econômicos (Tabela 4).

Tabela 2. Colaborações com empresas, universidades e centros de pesquisa com base no índice de integração estratégica (\%)

\begin{tabular}{cccc}
\hline Nível de integração estratégica & Médio-baixo & Elevado & Total \\
\hline Nenhuma colaboração & 23,9 & 15,1 & 19,6 \\
De 1 a 5 & 41,1 & 31,4 & 36,4 \\
Mais de 5 & 35,0 & 53,5 & 44,0 \\
Total & 100,0 & 100 & 100 \\
N. casos (dados faltantes: 55$)$ & 180 & 172 & 352 \\
\hline
\end{tabular}

Fonte: survey 2010 sobre as empresas-EPO

\section{Desempenho inovador e econômico}

Assim, chega-se ao desempenho das empresas-EPO durante os anos da crise econômica. As atividades de pesquisa e desenvolvimento realizadas nos anos precedentes tiveram, em geral, retornos econômicos positivos. De fato, quase um terço do faturamento das empresas-EPO deriva dos produtos patenteados. Não existe, todavia, uma ligação automática entre a pesquisa, o patenteamento, a inovação e seu rendimento econômico. A atividade de patenteamento é frequentemente assumida como indicador (proxy) da produção inovadora. Na realidade, ela capta, sobretudo, a atitude das empresas em relação à pesquisa. Ela identifica, em primeiro lugar, sua capacidade tecnológica e produção inventiva e, em segundo lugar, as estratégias competitivas (nem todas as patentes são 
comercializadas, já que algumas servem para bloquear a concorrência mais do que para inovar). Deve-se, portanto, vê-la de modo distinto da inovação empresarial, ou seja, da introdução de novos produtos e novas soluções tecnológicas de processo, organizacionais e de mercado, direcionadas a melhorar a capacidade competitiva e a posição de mercado das empresas.

Dito isso, junto à pesquisa e ao patenteamento, as empresas-EPO realizam também muitas inovações. No último triênio, quase todas introduziram no mercado um novo produto ou serviço (89\%); quase três quartos delas, uma inovação de processo (71\%) e organizacional (74\%); a metade, uma inovação em marketing (50\%). Também nesse caso trata-se de índices extraordinariamente elevados, considerando-se que na Itália, entre 2008 e 2010, somente $31 \%$ das empresas nacionais com mais de dez funcionários havia realizado uma inovação de produto/serviço ou de processo (média europeia, 39\%).

Vejamos, enfim, os desempenhos econômicos. Não obstante a crise econômica, no triênio de referência da primeira survey (2007-2009), as empresas-EPO registraram, em média, resultados positivos: o número de funcionários cresceu em $8 \%$ e o faturamento, em $19 \%$. O faturamento permaneceu estável somente em 2009. Tenha-se presente que, no mesmo ano, as empresas industriais italianas registraram uma pesada retração: no primeiro semestre de 2009, o índice da produção industrial caiu em $23 \%$, com um pico de $36 \%$ no setor de fabricação de maquinários e aparelhos mecânicos; no segundo semestre, a queda foi menor, mas de todo modo significativa (respectivamente $-14 \%$ e $-28 \%$ ).

Também a segunda sondagem, que se refere ao triênio seguinte (2010-2012), confirma o bom desempenho das empresas-EPO. Somente 23 das 407 empresas que responderam ao primeiro questionário cessaram suas atividades, isto é $6 \%$ contra uma média nacional de $18 \%$. Todas 
as outras empresas que aceitaram responder ao novo questionário continuaram a desenvolver atividades inovadoras registrando bons resultados econômicos: 41\% aumentou significativamente os recursos destinados a pesquisa e desenvolvimento; $45 \%$ aumentou o faturamento e $19 \%$ o manteve estável; 45\% aumentou o número de funcionários e 49\% preservou os níveis precedentes (somente 6\% reduziu o pessoal).

As empresas-EPO, portanto, mantiveram-se bem, inclusive no pior período da crise econômica internacional. E este é seu quarto aspecto distintivo. Contudo, entre as mais de 400 empresas que haviam respondido à primeira sondagem, evidencia-se uma acentuada heterogeneidade de desempenho, sobretudo no que se refere à evolução do faturamento e da produtividade. Aquelas que sentiram mais a crise são as empresas da mecânica, as maiores e as mais expostas aos mercados internacionais. Por outro lado, aquelas pequenas e médias - especialmente nos setores de alta tecnologia -, evidenciaram resultados melhores. Mas aquilo que mais diferencia seus desempenhos é a presença ou não de uma estratégia de inovação baseada na colaboração com atores externos. De fato, tanto na primeira fase da crise (survey 2010) como na seguinte (survey 2012), as empresas com parcerias inovadoras registraram um melhor desempenho ocupacional do que as demais (Tabela 3). Especialmente aquelas que evitaram a "armadilha do localismo". 
Sociologias, Porto Alegre, ano 19, no 46, set/dez 2017, p. 166-197

Tabela 3. Parcerias inovadoras e desempenho de emprego das empresas (valores \%)

Percentual de empresas que aumentaram

2007-2009 2010-2012 o número de empregados no período:

Parceria inovadora

Nenhuma

Ao menos uma

Localização geográfica das parcerias

Somente regionais

Regionais \& extrarregionais

Somente extrarregionais

No. Casos

Dados faltantes
25,0

39,3

51,8

30,4

43,0

36,4

225

182
33,3

53,7

55,2

141

14

Fonte: pesquisa 2010 e 2012 sobre as empresas com patentes EPO.

A capacidade de aproveitar os recursos externos, todavia, é fortemente condicionada pelo modelo organizacional interno escolhido. As empresas dotadas de uma elevada integração estratégica não somente possuem um maior número de parcerias inovadoras - conforme já mencionado (tab.2) -, mas também melhor desempenho econômico. Entre esses dois aspectos da estratégia empresarial, observa-se um interessante efeito de interação: são, de fato, as empresas que associam uma elevada integração interna e parcerias externas - que possuem uma cultura empresarial colaborativa e aberta - as que registram os melhores resultados de níveis de emprego e econômicos (Tabela 4). 
Tabela 4. Desempenho econômico e de nível de emprego das empresas segundo a estratégia empreendedora e organizacional (\%)

\begin{tabular}{cccc}
\hline Empresas com & Aumento dos empregados & $\begin{array}{c}\text { Elevada } \\
\text { performance } \\
\text { econômica }\end{array}$ \\
\cline { 2 - 4 } & $2007-2009$ & $2010-2012$ & $2007-2009$ \\
\hline Nenhuma parceria inovadora & 25,0 & 37,9 & 27,3 \\
Ao menos uma parceria: & & & 46,9 \\
Baixa integração estratégica & 35,2 & 40,4 & 54,9 \\
Alta integração estratégica & 42,7 & 64,8 & 166 \\
& & & 241 \\
N. casos & 225 & 141 & \\
Dados faltantes & 182 & 14 & \\
\hline
\end{tabular}

Fonte: pesquisa 2010 e 2012 sobre as empresas com patentes EPO.

A relevância específica da estratégia organizacional interna é confirmada também por uma análise estatística multivariada (regressão logística) conduzida nas empresas que forneceram dados sobre a evolução dos postos de trabalho entre 2010 e 2012. Para fins de parcimônia analítica, foi testado um modelo composto por poucas variáveis, que permite, porém, classificar corretamente $75 \%$ das empresas-EPO (contra 50\% do modelo com um só cruzamento). A análise mostra que a probabilidade de as empresas aumentarem ou não o número de empregos durante os anos da crise pode ser prevista pela combinação de quatro variáveis, somente duas das quais,

\footnotetext{
${ }^{12}$ As classes do "índice de performance econômica" foram obtidas a partir da mediana da distribuição. O índice foi construído de maneira aditiva, com base nas seguintes variáveis (entre parêntesis os coeficientes de ponderação utilizados): 1) produtividade do trabalho (faturamento por empregado) em 2009 (0,47); 2) variação da produtividade do trabalho entre 2007 e 2009 (0,40); 3) variação do faturamento entre 2007 e 2009 (0,48). Essas variáveis foram identificadas a partir de um fatorial (análise dos componentes principais; método de rotação varimax) que levou à extração de um fator que explica $57,4 \%$ da variância. O índice foi calculado somente para o período 2007-9, porque, para o período seguinte, o exíguo número de respostas obtidas sobre o faturamento tornaria o dado pouco significativo.
} 
porém, são significativas: o número de empregos no período precedente (2007-9) e a integração estratégica das empresas (Tabela 5) ${ }^{13}$.

Tabela 5. Regressão logística que prediz se uma empresa aumentou os empregos no período 2010-12

\begin{tabular}{cccccc}
\hline Resumo do modelo & $\mathbf{R}^{\mathbf{2}}$ de Nagelkerke & $\mathbf{X}^{\mathbf{2}}$ & $\mathbf{d f}$ & Sig. & $\begin{array}{c}\mathbf{N} . \\
\text { casos } \\
\text { inclusos }\end{array}$ \\
\cline { 2 - 6 } &, 407 & 33,91 & 4 &, 000 & 93 \\
\hline Variáveis na equação & B & E.S. & df & Sig. & Exp (B) \\
\cline { 2 - 6 } Presença de inovações (2007-9) &, 311 & 1,329 & 1 &, 815 & 1,364 \\
Parcerias inovadoras (2007-9) &,- 088 &, 872 & 1 &, 919 & 0,915 \\
Integração estratégica (2007-9) & 1,924 &, 543 & 1 &, 000 & 6,850 \\
Variação do no de empregados & 2,238 &, 579 & 1 &, 000 & 9,371 \\
(2007-9) & & & & & \\
Constante & $-2,755$ & 1,528 & 1 &, 071 &, 064 \\
\hline
\end{tabular}

Fonte dados: pesquisa sobre as empresas-EPO 2010 e 2012.

\section{As complementaridades radicadas da inovação}

O estudo conduzido sobre a geografia da inovação nos setores de alta e média-alta tecnologia na Itália fornece uma clara resposta aos três objetivos analíticos a que me propus no início deste artigo, sobre as relações entre empresas, inovação e território.

\footnotetext{
${ }^{13}$ Conduziu-se uma regressão logística binomial sobre as 93 empresas para as quais todas as informações relevantes estão disponíveis. Como variável dependente, utilizou-se o número de empregos entre 2010 e 2012: a primeira classe compreende as empresas em que o número de empregados permaneceu estável ou diminuiu, a segunda, aquelas em que esse aumentou. Como preditores, utilizaram-se quatro variáveis dicotômicas: 1 ) empresas com ao menos uma parceria inovadora no período 2007-9; 2) empresas com ao menos uma inovação no período 2007-9; 3) empresas com elevada integração estratégica no período 2007-9; 4) empresas que aumentaram o número de empregados no período 2007-9. Outras regressões desenvolvidas com finalidade de controle - com variáveis relativas às estratégias de mercado e à intensidade da pesquisa apresentaram resultados análogos.
} 
Objetivo 1: A pesquisa sobre a localização territorial das patentes-EPO, de fato, evidenciou uma elevada concentração geográfica da inovação, que foi confirmada posteriormente também pela survey conduzida nas empresas-EPO.

Objetivo 2: Quais são as características essenciais dessas últimas? Em primeiro lugar, trata-se de empresas sólidas que enfrentam mercados altamente competitivos. Na maioria dos casos, são empresas de médio e grande portes, que operam há muitos anos em cenários caracterizados por uma forte incerteza, ligada à rápida evolução da tecnologia e às mudanças da demanda. Em segundo lugar, são empresas altamente inovadoras; ou seja, empresas intensivas em pesquisa que realizam muitas inovações para o mercado. Em terceiro lugar, trata-se de empresas integradas que enfrentam as incertezas do cenário competitivo valendo-se de recursos que derivam do enraizamento social e territorial de suas atividades inovadoras. Finalmente, são empresas com bom desempenho econômico; possuem altos índices de faturamento, de produtividade e de exportações e demonstraram um discreto dinamismo também durante os anos mais difíceis da crise econômica internacional.

Conforme observado, um dos elementos mais característicos das empresas-EPO são as redes de colaboração externas. As parcerias inovadoras com universidades, centros de pesquisa e outras empresas são generalizadas. Esse enraizamento social da inovação tem uma clara matriz territorial. A maior parte das empresas-EPO, de fato, provém dos sistemas inovadores líderes da mecânica e da alta tecnologia, isto é, de áreas que registram a grande maioria das atividades de patenteamento italianas e que contam com uma disponibilidade de bens coletivos locais superior à média nacional. A isso se deve acrescentar que muitas das suas parcerias interessam a atores localizados no mesmo contexto territorial.

Dito isso, os spillovers cognoscitivos de que as empresas-EPO extraem suas vantagens competitivas não estão confinados exclusivamente à 
dimensão local. Aquelas com as melhores performances, de fato, conseguem conjugar as vantagens derivadas das redes curtas (locais e regionais) com as das redes longas (extrarregionais). Ou seja, mostram uma elevada capacidade de projetar-se para além de seus territórios de pertencimento. Não somente no front dos mercados, mas também naquele das relações de colaboração e aprendizagem. No entanto, também as redes longas são socialmente enraizadas. Grande parte das parcerias inovadoras não responde a uma lógica puramente econômica e de mercado, mas está fundada em colaborações duradouras, em que os laços sociais e de confiança têm um papel de grande relevância.

Objetivo 3: Esse enraizamento socioterritorial da inovação influencia positivamente o desempenho econômico das empresas-EPO. Mas não de todas indistintamente. Como mostrado, mesmo entre essas, se observa uma certa heterogeneidade na evolução dos níveis de emprego e de faturamento. A análise mostra que os melhores resultados estão associados a uma forte integração estratégica interna: um bom desempenho de capital humano e modalidades organizacionais que valorizam a flexibilidade e a coesão empresarial.

Em suma, os resultados da pesquisa mostram, em primeiro lugar, que as empresas-EPO estiveram em condições de alcançar bons resultados econômicos mesmo durantes os anos de crise econômica internacional, graças à sua capacidade inovadora e gerencial. Em segundo lugar, esse bom desempenho foi apoiado especificamente por: a) fatores contextuais (os bens coletivos locais e os recursos territoriais); b) fatores relacionais (as parcerias inovadoras); c) fatores de agência (a estratégia da empresa)

Esses elementos estão fortemente interligados, mas são, sobretudo, os "fatores de agência" os que desempenham um papel fundamental. É efetivamente graças a uma estratégia empresarial bem definida - orientada à colaboração interna e à abertura para o externo - que a empresa-EPO logra tirar vantagem das parcerias inovadoras e dos recursos existentes no 
contexto local e extralocal. Portanto, para obter bons resultados econômicos, é crucial a capacidade de usar meios complementares, por tipo e proveniência, equilibrando recursos de variedade e recursos de coesão localizados fora e dentro das empresas. Se, de um lado conhecimentos e competências diversificados aumentam a variedade necessária à inovação, de outro, o capital social e a integração estratégica potencializa sua capacidade de uso produtivo. Concluindo, as estratégias empresariais bem-sucedidas são, portanto, aquelas que aproveitam a complementariedade enraizada dos recursos inovadores, valendo-se, para fins econômicos, de mecanismos de aprendizagem socialmente e territorialmente estruturados.

Francesco Ramella é professor de Sociologia Econômica, na Universidade de Torino (Itália), onde é coordenador da Faculdade de Ciências Políticas e Sociais. \francesco.ramella@unito.it

\section{Referências}

1. ARUNDEL, A.; LORENZ, E.; LUNDVALL, B-Å.; VALEYRE, A. How Europe's Economies Learn: A Comparison of Work Organization and Innovation Mode for the EU-15. Industrial and Corporate Change. v. 16, n. 6, pp. 1175-210, 2007.

2. ASHEIM, B. T.; GERTLER, M. S. The Geography of Innovation: Regional Innovation Systems. In: FAGERBERG, J., MOWERY, D. C., NELSON, R. R. (Org.), The Oxford Handbook of Innovation. New York: Oxford University Press, p. 291-317, 2005.

3. BAGNASCO, A. Tre Italie. La problematica territoriale dello sviluppo italiano. Bologna: Il Mulino, 1977.

4. BECATTINI, G. The Marshallian Industrial District as a Socio-economic Notion. In: PYKE, F.; BECATTINI, G.; SENGENBERGER, W. (Org.), Industrial District and Inter-firm Cooperation in Italy. Geneva: IILS, ILO, 1990, pp. 37-51.

5. BECATTINI, G.; BELLANDI, M.; DE PROPRIS, L. (Org.). A Handbook of Industrial Districts. Cheltenham: UK, Northampton, USA: Edward Elgar, 2009.

6. BECATTINI, G.; RULLANI, E. Sistema locale e mercato globale. In: BECATTINI, G. Il distretto industriale. Torino: Rosenberg \& Sellier, 2000, pp. 93-116. 
7. BERGER, S. How We Compete. New York: Currency/Doubleday, 2005.

8. BIAGIOTTI, A. I sistemi locali leader nei brevetti. In: RAMELLA, F.; TRIGILIA, C. (Org.), Imprese e territori dell'Alta Tecnologia in Italia. Bologna: Il Mulino, 2010, pp. 75-97.

9. BOSCHMA, R. Proximity and Innovation: A Critical Assessment. Regional Studies, v. 39, n. 1, pp. 61-74, 2005.

10. BUCHANAN, J. M. An Economic Theory Of Clubs. Economica, v. 32, n. 1, pp. 1-14, 1965.

11. BURRONI, L.; TRIGILIA, C. (Org.). Le città dell'innovazione. Dove e perchè cresce I'alta tecnologia in Italia. Bologna: Il Mulino, 2011.

12. CAIRNCROSS, F. The Death of Distance. Cambridge: Harvard Business School Press, 1997.

13. CHESBROUGH, H. W. Open Innovation: The New Imperative for Creating and Profiting from Technology. Boston: Harvard Business School Press, 2003.

14. CIS. Types of co-operation partner for product and process innovation. Community Innovation Survey. 2010. Disponível em: http://epp.eurostat.ec.europa. eu/portal/page/portal/science_technology_innovation/data/database

15. COHEN, W. M.; LEVINTHAL, D. A. Absorptive Capacity: A New Perspective on Learning and Innovation. Administration Science Quarterly, v. 35, n. 1, pp. 123-33, 1990.

16. COHEN, W. M.; NELSON, R. R.; WALSH, J. P. Links and Inpacts: The Influence of Public Research on Industrial R\&D. Management Science, v. 48, n. 1, p. 1-23, 2002.

17. CROUCH, C.; LE GALÈS, P.; TRIGILIA, C.; VOELZKOW, H. Local Production Systems in Europe. Rise or Demise? Oxford: Oxford University Press, 2001.

18. DASGUPTA, P.; DAVID, P. A. Toward a New Economics of Science. Research Policy, v. 23, n. 5, pp. 493-4, 1994.

19. DONATIELLO, D.; RAMELLA, F. The Innovation Paradox in Southern Europe. Unexpected Performance During the Economic Crisis. South European Society and Politics, v. 22, n. 2, pp. 157-77, 2017.

20. GERTLER, M. S. Tacit Knowledge and the Economic Geography of Context, or the Undeniable Tacitness of Being (There). Journal of Economic Geography, v. 3, n. 1, pp. 75-99, 2003.

21. GERTLER, M. S. Rules of the Game: The Place of Institutions. Regional Economic Change, v. 44, n. 1, pp. 1-15, 2010. 
22. GEUNA, A.; ROSSI, F. The University and the Economy. Cheltenham: Edward Elgar, 2015

23. HAGEDOORN, J. Inter-firm R\&D Partnerships: An Overview of Major Trends and Patterns since 1960. Research Policy, v. 31, n. 4, pp. 477-92, 2002.

24. ISTAT (2010), Conti economici delle imprese, 25 marzo. Disponível em: http://www.istat.it/dati/dataset/20100325_00/.

25. JAFFE, A. B.; TRAJTENBERG, M.; HENDERSON, R. Geographic Localization of Knowledge Spillovers as Evidenced by Patent Citations. Quarterly Journal of Economics, v. 108, n. 3, pp. 577-98, 1993.

26. LUNDVALL, B- $\AA$.; JOHNSON, B. The Learning Economy. Journal of Industry Studies, v. 1, n. 2, pp. 23-42, 1994.

27. MASKELL, P.; MALMBERG, A. Localised Learning and Industrial Competitiveness. Cambridge Journal of Economics, v. 23, n. 2, pp. 167-86, 1999.

28. O'BRIEN, R. Global Financial Integration: The End of Geography. London: Royal Institute of International Affairs, 1992.

29. OECD. Measuring Innovation: A New Perspective. Paris: Oecd Publishing, 2010.

30. PAVITT, K. Knowledge about Knowledge since Nelson \& Winter: A Mixed Record. SPRU Working Paper Series 83. Sussex: University of Sussex, June, pp. 1-21, 2002.

31. POLANYI, M. The Tacit Dimension. New York: Anchor Books, 1966.

32. POWELL, W. W.; GRODAL, S. Networks of Innovators. In: FAGERBERG, J.; MOWERY, D. C.; NELSON, R. R. (Org.). The Oxford Handbook of Innovation. New York: Oxford University Press, p. 56-85, 2005.

33. RAMELLA, F. The "Enterprise of Innovation" in Hard Times. Corporate Culture and Company Performance in Italy. European Planning Studies, pp. 1-22, 2017a, pubblicato online 10 maggio 2017, http://www.tandfonline.com/doi/full/1 0.1080/09654313.2017.1321621

34. RAMELLA, Francesco. Sociologia da Inovação Econômica, Porto Alegre: Editora da UFRGS. No prelo, 2017b.

35. RAMELLA, F.; TRIGILIA, C. (Org.). Imprese e territori dell'Alta Tecnologia in Italia. Bologna: II Mulino, 2010a.

36. RAMELLA, F.; TRIGILIA, C. (Org.). Invenzioni, inventori e territori in Italia. Bologna: Il Mulino, 2010b. 
37. RODRÍGUEZ-POSE, A. Economists as Geographers and Geographers as Something Else: On the Changing Conception of Distance in Geography and Economics. Journal of Economic Geography, v. 11, n. 2, pp. 347-56, 2011.

38. TRIGILIA, C. La costruzione sociale dell'innovazione. Economia società e territorio. Quaderni della Biblioteca del Polo Universitario Città di Prato, n. 4, pp. 1-56, 2007.

39. TRIGILIA, C. Work and Politics in the Third Italy's Industrial District. In: PYKE, F.; BECATTINI, G.; SENGENBERGER, W. (Org.), Industrial District and Inter-firm Cooperation in Italy, Geneva: IILS, ILO, 1990, pp. 160-84.

40. TRIGILIA, C.; BURRONI, L. Italy: rise, decline and restructuring of a regionalized capitalism. Economy and Society, v. 38, n. 4, pp. 630-53, 2009.

41. ZUCKER, L. G.; DARBY, M. R. Star Scientists and Institutional Transformation: Patterns of Invention and Innovation in the Formation of the Biotechnology Industry. Proceedings of the National Academy of Sciences, v. 93, n. 23, pp. 12709-16, 1996.

Recebido: 13.01.2017

Aceite final: 24.06.2017 